\title{
Optimizing efficiency and skill utilization: Analysis of genetic counselors' attitudes regarding delegation in a clinical setting
}

\author{
Parker Read $^{1}$ | Beverly M. Yashar ${ }^{2}$ | Linda Robinson ${ }^{1}$ | Monica Marvin ${ }^{2}$
}

${ }^{1}$ Simmons Comprehensive Cancer Center, UT Southwestern Medical Center, Dallas, TX, USA

${ }^{2}$ Department of Human Genetics, University of Michigan, Ann Arbor, MI, USA

\section{Correspondence}

Parker Read, 400 W. Magnolia Ave., Fort Worth, TX 76104, USA.

Email: Parker.Read@UTSouthwestern.edu

Funding information

University of Michigan Rackham Graduate

School Student Research Grant

\begin{abstract}
This study assessed genetic counselors' (GCs) perceptions of delegation as a tool to increase workforce efficiency and help meet the current gap between the number of genetic service providers and the number of patients. GCs were recruited to participate via an online survey that assessed activities (categorized as typical genetic counseling, administrative, or professional development) performed by a clinical genetic counselor. Respondents indicated which activities represent their largest time consumers, their willingness to delegate these activities, and barriers to and perceived outcomes of delegation. Overall, respondents indicated that they spend $25 \%$ of their time performing administrative activities that they would largely be willing to delegate; however, respondents were generally unwilling to delegate many typical genetic counseling and professional development activities, citing concerns regarding accuracy and liability, and highlighting the belief that these activities constitute the core role of a genetic counselor. Respondents indicated that delegation of time-consuming administrative activities would increase access to genetic services and improve job satisfaction. Additionally, differences were identified among clinical specialties regarding which activities were selected as top time consumers, indicating that potential targets of re-allocation of time or delegation may be variable. This research indicates a need to reduce the number of administrative tasks in which GCs are directly involved to re-allocate time toward core responsibilities, direct patient care, and professional development, the result of which is more efficient use of the GC skill-set.
\end{abstract}

\section{KEYWORDS}

access, delegation, efficiency, genetic counseling, genetic counselors, genetic services, optimization, practice models, service delivery, time-consuming, workforce

\section{1 | INTRODUCTION}

Genetic counselors (GCs) are healthcare providers with unique skills and knowledge that result from advanced training across several domains including: (a) Genetics Expertise and Analysis; (b) Interpersonal, Psychosocial, and Counseling Skills; (c) Education; and (d) Professional Development \& Practice (Accreditation Council for Genetic Counseling, 2015). This training results in versatile healthcare providers with a well-defined scope of practice, the value of which has been recognized by clinicians, patients, payers, and other stakeholders in a variety of settings (Hampel et al., 2009; Hartmann, Veach, MacFarlane, \& LeRoy, 2015; Paneque, Mendes, Guimaraes, Sequeiros, \& Skirton, 2015).

An increased awareness and recognition of the value of genetic services have led to significant demand for GCs, and the current study seeks to identify opportunities for optimizing GC 
time and efficiency to support this growth. The clinical indications warranting genetic counseling have expanded within traditional settings, such as reproductive, pediatric, and cancer disciplines, as well as within other specialties like cardiology, neurology, and pharmacology (National Society of Genetic Counselors, 2018). In each of these areas, the landscape of genetic testing is dynamic; there are currently over 74,000 genetic testing products on the market, with 14 new products entering the market every day (Concert Genetics, 2018). While the majority of these are single gene tests, an increasing number are more complex, including multigene panels, whole exome testing, etc. (Concert Genetics, 2018). Given that many healthcare providers lack formal genetics education and are more likely to order an inappropriate test, interpret results incorrectly, and/or make inappropriate management decisions (Cox et al., 2012; Kurian et al., 2017, 2018), the expertise of GCs is paramount, and in some cases mandated, to enable the most clinically appropriate, well-informed, and cost-effective use and interpretation of genetic tests (Miller et al., 2014; Mvundura, Grosse, Hampel, \& Palomaki, 2010).

This increasing demand for GCs across multiple sectors of healthcare, including clinical, commercial, and other domains, has led to concerns about a shortage of genetic counselors (Hoskovec et al., 2018; Pan, Yashar, Pothast, \& Wicklund, 2016) such that the supply of GCs in direct patient care will likely not meet projected demand until 2030 (Hoskovec et al., 2018). The genetic counseling profession has adopted multifaceted strategies to address this shortage including (a) expansion of the number and size of Accreditation Council for Genetic Counseling (ACGC) accredited Genetic Counseling Programs, (b) the adoption of alternative service delivery models such as telephone genetic counseling, telemedicine, and group counseling (Cohen et al., 2013; Kinney et al., 2014; Platten et al., 2012), (c) the development of genetic counseling assistant positions (PirzadehMiller, Robinson, Read, \& Ross, 2017), and (d) collaborations with non-genetics professionals to provide genetic services for routine indications (Cohen \& Mcllvried, 2013; O'Shea et al., 2011). Per the 2018 National Society of Genetic Counselors (NSGC) Professional Status Survey, $62 \%$ of GCs are utilizing multiple service delivery models (National Society of Genetic Counselors, 2018) and genetics clinics are implementing online tools that improve efficiency by allowing patients to share their own medical information prior to a clinical appointment (Pritzlaff et al., 2014).

As efforts to address workforce shortages are ongoing, the impact of increasing demands on the genetic counseling workforce and care delivery remains significant. Some GCs have transitioned away from direct patient care, citing feeling overworked and undervalued and perceiving poor management and lack of support (Cohen \& Tucker, 2018). Those GCs that continue to work in clinical care note effects on patient care such as reduction in time spent with patients and longer wait times for appointments (Wham et al., 2010). However, even as a stretched genetic counseling workforce faces unprecedented clinical demands, many genetic counselors continue to be responsible for tasks and activities that do not require their unique skills or knowledge, detracting from overall quality and efficiency of care (VandenBoom, Trepanier, \& Carmany, 2018; Wham et al., 2010).

Minimizing duplication, creating streamlined processes and increasing efficiency are common goals for all areas of medical care that apply to both tangible resources, as well as the unique skills of individual practitioners. Accordingly, the NSGC identified the development of practice tools and resources to support efficient delivery of genetic services and promote collaborative care as a component of its 2016-2018 and 2019-2021 Strategic Plans (nsgc.org).

This research is intended to identify opportunities for optimizing GC time and efficiency to support high-quality services by (a) determining time-consuming tasks that GCs are willing to delegate, (b) assessing GC perceptions of potential outcomes from the delegation of their most time-consuming tasks, (c) identifying barriers to delegation. Furthermore, by not only highlighting where GCs spend most of their time, but also what they would be willing to delegate, we hope to foster a self-awareness of core GC tasks and how GCs define, interact with, and utilize clinical teams.

\section{2 | METHODS}

\subsection{Participants and survey distribution}

Survey respondents were recruited between November 12, 2015 and December 11, 2015 via the email listings of the NSGC and the American Board of Genetic Counseling (ABGC) and invited to complete a survey (Table S1; Study Survey) hosted on a Qualtrics website. Some questions were only displayed based on respondents' answers to previous questions, so the survey had a minimum of 35 items and a maximum of 38 items. Since the study was targeted at clinical GCs, respondents were asked initially if they have spent at least $50 \%$ of their professional time in a clinical setting over the past 12 months; only those who responded yes were eligible to participate. The study was approved by the University of Michigan IRB (HUM00105474).

\section{2 | Instrumentation}

The survey was composed of three sections (demographics, clinical activities \& roles, and outcomes of/barriers to delegation). Demographic information ( $n=12$ questions) included clinical specialty, graduate degree type(s) and year awarded, and current GC licensure status. Clinically relevant information included the number of GCs in the clinical team and the number of full-time equivalent GCs (FTEs), patient volume, and hours worked. Respondents identified all individuals (i.e. physician, medical assistant, nurse, genetic counseling assistant, etc.) considered as part of their clinical team.

\subsubsection{Activities performed in the clinical setting}

A literature review was conducted to build a comprehensive list of potential activities performed by a GC (Accreditation Council for Genetic Counseling, 2015; Hampel et al., 2009; National Society of Genetic Counselors, 2014). Forty-four individual activities were 
divided into three categories (Table S1): (a) typical genetic counseling activities ( $N=18)$, (b) administrative activities ( $N=13)$, and (c) professional development activities ( $N=13$ ). For each activity, respondents defined current practices (see below) and perspectives on hypothetical activity delegation. Respondents were asked to indicate which individual(s) in their clinic typically contribute(s) to each activity. Responses accounted for collaboration between numerous individuals, including GCs. The data collected about current practices included percentage of time spent performing individual activities within each of the three categories (total time in all three categories equals $100 \%$ of respondents' time) and the five activities in each category that account for the largest portion of their time. From these five activities, respondents then indicated their willingness to delegate a portion of their responsibility, the professional to whom they would be willing to delegate (including personnel not currently in their clinic), and approximately what proportion of their current responsibility they would be willing to delegate, ranging from minimal (the GC retains the majority of the responsibility) to complete (no need for direct GC involvement).

\subsection{2 | Free response questions}

Respondents were asked several open-ended questions that explored GCs' attitudes toward delegation of top time-consuming activities, assessed the potential impact of delegation, and asked about barriers to delegation and the expansion of GCs' clinical teams. These questions were posed in such a way that respondents were asked about activities in aggregate (i.e. Of all the GC activities/administrative activities/professional development activities that they were unwilling to delegate, what were some of their primary reasons?).

\section{3 | Data analysis}

\subsection{1 | Statistical analysis}

Statistical analysis was performed using SPSS software (version 23) (IBM Corp, 2015). Data analysis included descriptive statistics, chisquare tests to compare top time consumers between clinical specialties within each of the three task categories, and independent $t$-tests to assess differences between clinical specialties with regard to average percentage time spent on activities in each of the three categories in aggregate. An alpha level of .05 was used for all statistical tests.

\subsection{2 | Qualitative analysis}

Responses to open-ended questions were analyzed by the study team using descriptive coding (Saldana, 2013) to identify unifying themes that explained why respondents would be unwilling to delegate certain activities, as well as perceived outcomes of delegation. Initially, all excerpts were reviewed and coded by the principal investigator. Coding categories and code application were reviewed by two additional team members. The most commonly applied codes were reviewed and discussed by the study team.

\section{3 | RESULTS}

Overall, respondents reported that they spend $25 \%$ of their time performing administrative activities that they would largely be willing to delegate and indicated that delegation of these time-consuming administrative activities could increase access to genetic services and improve job satisfaction. However, respondents were generally unwilling to delegate many typical genetic counseling and professional development activities, noting the importance of the provision of high-quality care, the belief that these activities constitute the core role of a genetic counselor, and that performing these activities provides job satisfaction.

\section{1 | Sample demographics (Table 1)}

Of the initial group of respondents that elected to begin the survey ( $N=519), 97(18.7 \%)$ were ineligible due to having spent less than $50 \%$ of their time in a clinical setting over the last 12 months. This left a final study population of 422 respondents. Not all respondents completed the entire survey leading to variability in the sample size for individual items.

There was significant diversity with regard to clinical specialty, with $41.0 \%$ of respondents from cancer, $25.7 \%$ from prenatal, $17.0 \%$ from pediatrics, and $16.3 \%$ from "other specialty," which consisted primarily of general genetics. This population differs significantly from respondents to the 2014 NSGC Professional Status Survey (PSS), in which $29 \%$ of respondents reported cancer as their primary specialty, $X^{2}(1, N=1713)=21.6, p<.0001,35 \%$ reported prenatal, $X^{2}(1, N=1713)=13.1, p<.001,12 \%$ reported pediatrics, $X^{2}(1, N=1713)=7.25, p<.01$, and $24 \%$ reported other $X^{2}(1$, $N=1713)=10.6, p<.01$ (National Society of Genetic Counselors, 2014).

Respondents were asked to provide information about current staffing in their individual clinics (Table 1). Sixty-nine percent indicated that their clinic is currently fully staffed in terms of GCs. Overall the average number of GCs in an individual clinic was 3.84 (median $=3$ ) and $23.5 \%$ of respondents indicated that they were the only genetic counselor in their clinical team. Average patient load among all respondents was approximately 10 patients/week $(S D=5.1)$. Additionally, $71 \%$ of respondents indicated that they typically work overtime, and reported working an average of $5.75 \mathrm{hr}$ of overtime per week $(S D=3.68)$. This is consistent with $69 \%$ of GCs reporting that they work overtime per the 2014 PSS. Lastly, there were differences noted in average patient volume by clinical specialty. Cancer GCs ( $M=9.36, S D=3.44)$ reported seeing 2.2 fewer patients per week than non-cancer $G C s(M=11.56, S D=5.81)$, $\mathrm{t}(346)=-4.09, p<.0001$, while prenatal $\mathrm{GCs}(M=13.83, \mathrm{SD}=5.72)$ reported seeing 4.3 more patients per week than non-prenatal GCs $(M=9.54, S D=4.32), \mathrm{t}(346)=7.41, p<.0001$. Additionally, 
TABLE 1 Demographic information

$\begin{array}{ll}\text { Clinical specialty }(N=394) & \\ \text { Cancer } & 41.0 \%(N=162) \\ \text { Prenatal } & 25.7 \%(N=101) \\ \text { Pediatrics } & 17.0 \%(N=67) \\ \text { Other } & 16.3 \%(N=64)\end{array}$

Genetic counselor state licensure status ( $N=392)$

$\begin{array}{ll}\text { Licensed } & 44.1 \%(N=173) \\ \text { Not licensed } & 55.9 \%(N=219)\end{array}$

Does the individual typically work overtime $(N=366)$ Yes

No

$29.0 \%(N=106)$

On average, how much overtime per week $(N=250)^{\text {a }}$

More than $15 \mathrm{hr}$

$1.6 \%(N=4)$

$10.5-15 \mathrm{hr}$

$5.6 \%(N=14)$

$5.5-10 \mathrm{hr}$

$28.0 \%(N=70)$

$1-5 \mathrm{hr}$

$64.8 \%(N=162)$

Average weekly patient volume - clinic $(N=343)$

100 or more

$4.1 \%(N=14)$

$80-99$

$2.6 \%(N=9)$

60-79

$8.5 \%(N=29)$

40-59

$14.0 \%(N=48)$

20-39

$32.4 \%(N=111)$

$0-19$

$38.5 \%(N=132)$

Average weekly patient volume - respondent $(N=348)$

$\begin{array}{lc}21-25 & 4.3 \%(N=15) \\ 16-20 & 9.5 \%(N=33) \\ 11-15 & 25.9 \%(N=90) \\ 6-10 & 46.0 \%(N=160) \\ 0-5 & 14.4 \%(N=50)\end{array}$

Is clinic fully staffed with genetic counselors $(N=387)$

Yes

$68.7 \%(N=266)$

No

$31.3 \%(N=121)$

Number of clinical genetic counselors on staff $(N=366)$

$16-20$

$1.1 \%(N=4)$

$11-15$

$5.5 \%(N=20)$

6-10

$12.3 \%(N=45)$

1-5

$81.1 \%(N=297)$

Nongenetic counselor staff in clinical team $(N=349)$

Physician

$87.1 \%(N=304)$

Administrative personnel

$83.5 \%(N=289)$

Nurse (LPN, RN, CNA, etc.)

$41.5 \%(N=135)$

Medical assistant

$38.2 \%(N=124)$

Nurse practitioner

$26.8 \%(N=83)$

Dietician

$24.4 \%(N=75)$

Social worker

$20.0 \%(N=62)$
TABLE 1 (Continues)

Genetic counseling assistant

$17.6 \%(N=52)$

Physician assistant

$6.6 \%(N=20)$

Abbreviations: CNA, certified nursing assistant; LPN, licensed practical nurse; $\mathrm{RN}$, registered nurse.

aQuestion only visible to respondents that answered "Yes" to working overtime.

Sample size $N$ varies between questions due to drop-off over the course of the survey/failure to answer the question, as responses to these questions were not required to continue in the survey.

GCs categorized as "other specialty" ( $M=9.32, S D=4.91)$ reported seeing 1.57 fewer patients per week than all other GCs $(M=10.9$, $S D=5.07), \mathrm{t}(346)=-2.13, p=.034$.

\section{2 | Distribution of genetic counselor time}

Survey respondents were asked to indicate what percentage of their time is spent performing activities within each of three categories (typical genetic counseling, administrative, and professional development). Across all respondents an average of $63.7 \%$ of GC time was reported to be spent performing activities in the typical genetic counseling category, $25.0 \%$ in the administrative category, and $11.3 \%$ in professional development category. When this distribution was analyzed for differences based on clinical specialty, relatively small differences were identified (Figure 1). Prenatal genetic counselors $(M=67.0 \%, S D=12.7)$ reported spending approximately $4.54 \%$ more of their time on typical genetic counseling activities compared to all other genetic counselors $(M=62.5 \%, S D=14.3$ ), $\mathrm{t}(329)=2.61, p<.01$, and approximately $3.3 \%$ less on administrative activities $(M=22.6 \%, S D=10.9)$ than all other genetic counselors $(M=25.9 \%, S D=12.9), t(329)=-2.11, p<.05$. Pediatric genetic counselors $(M=30.0 \%, S D=14.3)$ spent approximately $5.84 \%$ more of their time on administrative activities than all other genetic counselors $(M=24.1 \%, S D=11.9), t(329)=3.14, p<.01$. No other significant differences were identified among specialties with regard to estimated percentage of time spent across the three task categories when compared to all other respondents.

\subsection{Top time-consuming activities (Table 2) and willingness to delegate (Table 3 )}

\subsection{1 | Administrative activities}

Among the 13 administrative activities in which genetic counselors participated, respondents were asked to select up to five activities which they felt account for the majority of their time. For individual activities that respondents indicated they performed in their clinical setting, the top five administrative time consumers across all respondents included completion of test ordering forms $(77 \%$; 244/317 respondents participate in this task), contacting genetic testing laboratories regarding ongoing testing/monitoring receipt of and management of incoming genetic test results (65\%; 209/320), patient scheduling/managing incoming referrals/contacting patients 
FIGURE 1 Distribution of genetic counselor time

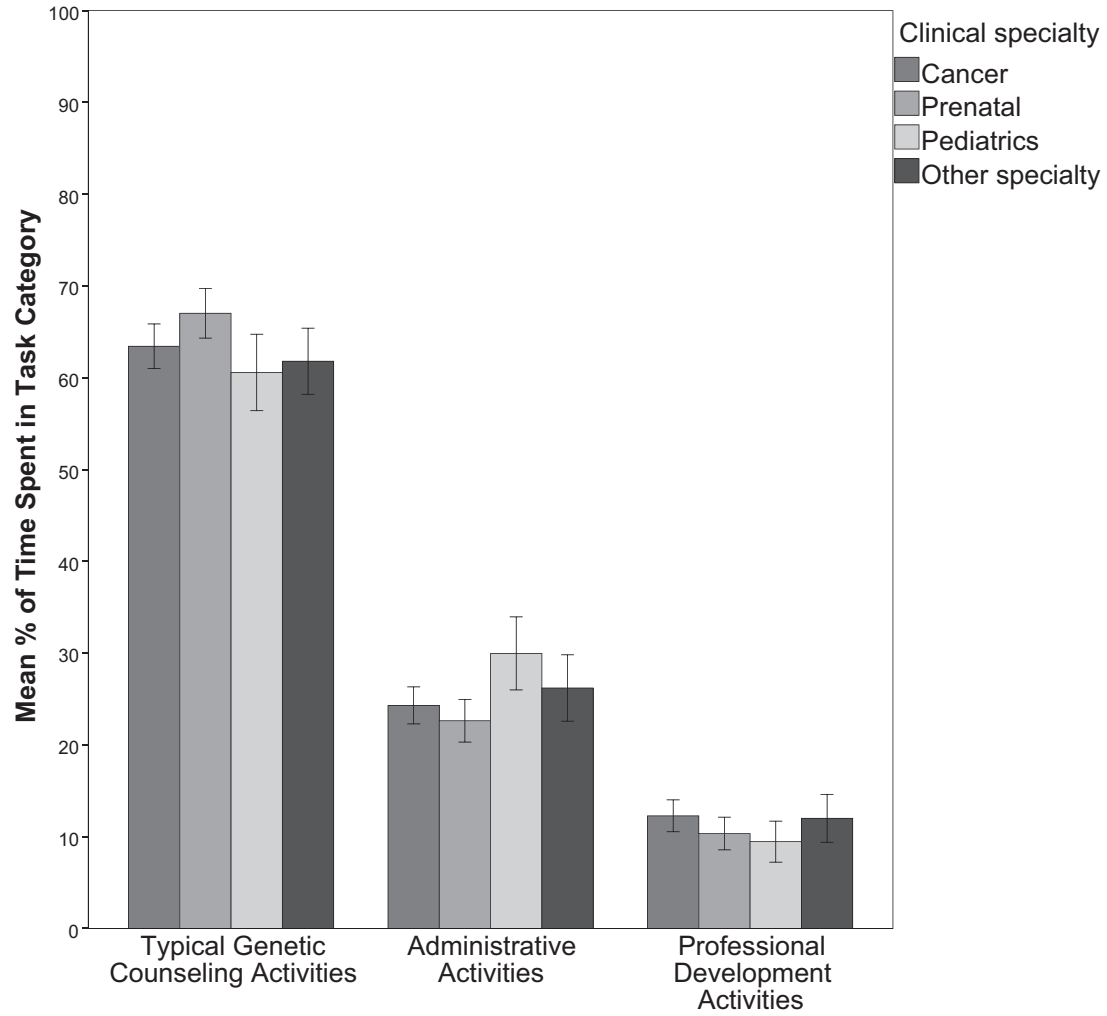

prior to their appointment (64\%; 123/191), management of insurance authorization and appeals (61\%; 155/255), and copying/printing/scanning/faxing documents (50\%; 138/278).

Among the top five administrative time consumers, two activities differed when comparing individual clinical specialties to all other respondents (Table 2). Prenatal GCs were less likely to report scheduling/managing referrals as a top time consumer $(50 \%$; $21 / 42$ ) compared to GCs in other specialties (69\%; 102/149), $X^{2}$ $(1, N=191)=4.87(p<.05)$, and pediatric GCs $(81 \% ; 34 / 42)$ were more likely than GCs in other specialties $(57 \% ; 121 / 213)$ to report obtaining insurance authorization as a top time consumer, $X^{2}(1$, $N=255)=8.58(p<.01)$.

Respondents indicated considerable willingness to delegate their top administrative time consumers, ranging from $71 \%(145 / 204)$ willing to delegate some portion of contacting genetic testing laboratories regarding ongoing testing/monitoring receipt of and management of incoming genetic test results to $100 \%$ (133/133) willing to delegate some portion of copying/printing/scanning/faxing documents (Table 3 ).

\subsection{2 | Typical genetic counseling activities}

Similar to the evaluation of their administrative activities, respondents selected up to five activities which they felt account for the majority of their time within the category of typical genetic counseling activities. All 18 typical genetic counseling activities in this category were represented as a top time consumer by some percentage of respondents. The top five time consumers included clinical documentation (81\%; 264/324), presentation of testing options and informed consent for genetic testing (69\%; 227/329), obtaining complete family history $(55 \% ; 180 / 326)$, patient education regarding clinical presentation/diagnosis/management, etc. (52\%; 164/318), and reviewing relevant literature and medical records/development of counseling plan (50\%; 165/329).

Differences among clinical specialties with regard to top time consumers were more common among typical genetic counseling activities than for administrative or professional development activities (Table 2). Of note, some of the largest differences between clinical specialties were observed in presentation of testing options and informed consent for genetic testing, obtaining complete family history, and patient education regarding clinical presentation/diagnosis/management. Pediatric genetic counselors were much less likely to report presentation of testing options and informed consent for genetic testing as a top time consumer $(29 \%$; $15 / 52$ ) compared to GCs in other specialties (77\%; 212/277), $X^{2}$ $(1, N=329)=46.55(p<.001)$, while cancer GCs were more likely to report patient education regarding clinical presentation/diagnosis/management as a top time consumer (69\%; 97/141) compared to GCs in other specialties (38\%; 67/177), $X^{2}(1, N=318)=30.08$ $(p<.001)$. Additionally, pediatric GCs were less likely to report obtaining complete family history as a top time consumer $(32 \%$, $16 / 50)$ compared to GCs in other specialties $(60 \% ; 164 / 276) X^{2}(1$, $N=326)=12.87(p=.001)$.

Overall willingness to delegate typical genetic counseling activities was low when compared to administrative activities (Table 3), particularly among the top five time consumers, ranging from $9 \%$ 
TAB LE 2 Variation in top time consumers among clinical specialties

\begin{tabular}{|c|c|c|c|c|c|c|c|c|c|}
\hline & \multicolumn{2}{|l|}{ Cancer } & \multicolumn{2}{|l|}{ Prenatal } & \multicolumn{2}{|l|}{ Pediatric } & \multicolumn{2}{|c|}{ Other specialty } & $\begin{array}{l}\text { All specialties } \\
\text { \% Reported } \\
\text { as top time } \\
\text { consumer }\end{array}$ \\
\hline \multicolumn{10}{|l|}{ Administrative activities } \\
\hline $\begin{array}{l}\text { Completing test ordering } \\
\text { forms }\end{array}$ & 77 & $>0.999$ & 78 & 0.879 & 71 & 0.356 & 80 & 0.715 & 77 \\
\hline $\begin{array}{l}\text { Scheduling/managing } \\
\text { referrals/contact- } \\
\text { ing patients prior to } \\
\text { appointment }\end{array}$ & 70 & 0.215 & 50 & 0.044 & 70 & 0.461 & 63 & 0.847 & 64 \\
\hline $\begin{array}{l}\text { Copying/printing/scan- } \\
\text { ning/faxing documents } \\
\text { and records }\end{array}$ & 47 & 0.398 & 57 & 0.164 & 49 & $>0.999$ & 47 & 0.741 & 50 \\
\hline \multicolumn{10}{|c|}{ Typical genetic counseling activities } \\
\hline Clinical documentation & 91 & $<0.001$ & 79 & 0.519 & 83 & 0.842 & 58 & $<0.001$ & 81 \\
\hline $\begin{array}{l}\text { Presentation of testing op- } \\
\text { tions/informed consent }\end{array}$ & 76 & 0.022 & 86 & $<0.001$ & 29 & $<0.001$ & 62 & 0.249 & 69 \\
\hline $\begin{array}{l}\text { Obtaining complete family } \\
\text { history }\end{array}$ & 61 & 0.092 & 61 & 0.259 & 32 & 0.001 & 54 & 0.878 & 55 \\
\hline $\begin{array}{l}\text { Patient education - clinical } \\
\text { presentation/diagnosis/ } \\
\text { management }\end{array}$ & 69 & $<0.001$ & 42 & 0.040 & 39 & 0.062 & 30 & 0.002 & 52 \\
\hline $\begin{array}{l}\text { Managing/developing clini- } \\
\text { cal program }\end{array}$ & 62 & 0.057 & 47 & 0.081 & 40 & 0.039 & 68 & 0.126 & 56 \\
\hline $\begin{array}{l}\text { Development of tools for } \\
\text { professional education }\end{array}$ & 45 & 0.424 & 58 & 0.048 & 43 & 0.432 & 45 & 0.638 & 48 \\
\hline $\begin{array}{l}\text { Delivery of presentations/ } \\
\text { lectures/etc. for profes- } \\
\text { sional education }\end{array}$ & 38 & 0.412 & 50 & 0.081 & 41 & $>0.999$ & 36 & 0.418 & 41 \\
\hline $\begin{array}{l}\text { Development of tools/ } \\
\text { presentations/events for } \\
\text { patient education }\end{array}$ & 44 & 0.415 & 37 & 0.422 & 44 & 0.738 & 37 & 0.627 & 41 \\
\hline
\end{tabular}

$p$-values were calculated based on chi-square comparisons between each individual specialty and all other specialty categories combined. Sample sizes are not included as the value varied between questions due to the survey structure and the use of incomplete responses

(21/225) willing to delegate some portion of presentation of testing options/informed consent for genetic testing to 33\% (58/176) willing to delegate some portion of obtaining complete family history.

\subsection{3 | Professional development activities}

The top five time-consuming activities within the category of professional development activities are supervision of students
(72\%; 212/295), managing/developing the clinical program (56\%; $162 / 289$ ), development of tools/presentations/teaching/events for professional education (48\%; 149/310), delivery of presentations/ lectures/events for professional education (41\%; 125/303), and development of tools/presentations/community outreach/events for patient education (41\%; 125/305).

Among these top five time consumers, three differed significantly when comparing individual clinical specialties to all other respondents 
TAB LE 3 Genetic counselor willingness to delegate top time consumers

$\%$ of genetic counselors willing to delegate some portion of their role

Administrative activities

Completing test ordering forms $(N=237)$

76

Contacting genetic testing labs/monitoring $\quad 71$ receipt of genetic test results $(N=204)$

Scheduling/managing referrals/contacting patients prior to appointment $(N=120)$

Management of insurance authorization/ appeals $(N=153)$

Copying/printing/scanning/faxing documents and records $(N=133)$

Typical genetic counseling activities

Clinical documentation $(N=261)$

Presentation of testing options/informed consent $(N=225)$

Obtaining complete family history $(N=176)$

33

Patient education - clinical presentation/ 12

diagnosis/management $(N=162)$

Reviewing literature and records/developing $\quad 10$ counseling plan $(N=162)$

Professional development activities

Supervision of students $(N=208)$

Managing/developing clinical program

$(N=156)$

Development of tools for professional

education $(N=142)$

Delivery of presentations/lectures/etc. for professional education $(N=122)$

Development of tools/presentations/events for patient education $(N=120)$

Sample size $N$ represents the total number of respondents that indicated whether or not they would be willing to delegate that activity, and varies across activities since respondents were only asked about their willingness to delegate a particular activity if they previously indicated that activity as a top time consumer.

(Table 2). Prenatal genetic counselors were more likely to report supervision of students (85\%; 68/80) as a top time consumer compared to genetic counselors in other specialties $(67 \% ; 144 / 215) X^{2}$ $(1, N=295)=9.37(p<.01)$. They were also more likely to report development of professional education tools (58\%; 45/77) as a top time consumer compared to genetic counselors in other specialties $(45 \%$; $104 / 233) X^{2}(1, N=310)=4.42(p<.05)$. Lastly, pediatric genetic counselors were less likely $(40 \% ; 16 / 40)$ than genetic counselors in other specialties $(59 \% ; 146 / 249)$ to report managing their clinical program as a top time consumer, $X^{2}(1, N=289)=4.86(p<.05)$.

Overall willingness to delegate professional development activities is low (Table 3), particularly among the top five time consumers, ranging from $10 \%(20 / 208)$ willing to delegate some portion of supervision of students to $38 \%(46 / 120)$ willing to delegate some portion of development of tools/presentations/community outreach/events for patient education.

Linear regression analysis identified no statistical significance associating any of the following demographic data points with top time consumers or willingness to delegate across any of the three categories of activities: number of GCs in the clinic, whether the clinic was fully staffed, average patient volume, and whether the GC worked overtime.

\subsection{Potential barriers to delegation}

A variety of themes were identified that explained why participants would be unwilling to delegate tasks. Common reasons provided for unwillingness to delegate genetic counseling activities were the feeling that GCs are the most qualified individuals to perform these activities, the belief that these activities are core GC responsibilities, and the opinion that proper case management necessitates the activities are performed by GCs (i.e. GCs are most aware of the clinical aspects of cases and are most prepared to deal with additional follow-up from an administrative perspective). Other important themes related to genetic counseling activities included: enjoyment of activities ("I would not delegate counseling activities as those are my favorite part of the day"), and feeling that delegation is either not feasible ("...already have full roles with delegated responsibilities") or not necessary ("Performing these tasks is already a joint effort between myself and the physicians and I am happy with the amount spent on these tasks). With regard to administrative activities, many respondents were reluctant to delegate because this could compromise accuracy, especially in relation to completing test requisitions. Importantly, a common theme regarding unwillingness to delegate professional development activities was that these contribute to ongoing career growth and are enjoyed by GCs. Of particular note, GC student supervision was regularly identified as a professional activity that only genetic counselors should perform.

When respondents were asked about the addition of personnel in their clinic that may be able to take on certain activities, lack of funding was cited as a common barrier. One respondent noted "we have considered having a genetic counseling assistant to take care of prior-authorizations (and follow-up on these), packaging samples, completing and copying TRFs. We have not been able to hire anyone because the institution lacks funds to support this." Additionally, respondents commonly cited a lack of institutional support, with one respondent noting "I would love to incorporate more staff into our clinical team, but we do not have a lead genetic counselor or supervisor to speak on our behalf and the business director/other lead staff does not believe we need the help (although we all work well over 50-60 hr per week)."

\subsection{Outcomes of delegation of top time- consuming activities}

Various themes arose that highlight the perceived outcomes of delegation, such as the ability to increase access to services and improve 
quality of care, the ability to focus more on core activities that highlight the skill-set obtained through genetic counseling training, and improvement in work quality of life and job satisfaction. One respondent stated "I think it would allow me to see more patients. We currently have a 20-month waitlist for a genetic counseling appointment which is completely unacceptable. The GCs in our clinic spend way too much time doing administrative activities." Additionally, respondents indicated that they feel delegating some portion of their top time-consuming activities in aggregate would increase time that could be spent on typical GC activities and professional development activities ("The goal would be to free up more of my time as a GC for other activities (research, education, etc.) that is taken up by administrative roles..."), help reduce overtime, and improve overall job satisfaction ("I would have more time to focus on the parts of my job that I enjoy and would spend less time working overtime"). A small number of respondents ( 8 out of $N=26$ ) felt that the impact on their clinic would be minimal ("I currently have enough time to do all my work, so delegating wouldn't impact me too much right now").

\section{DISCUSSION}

In light of the increasing demand for genetic services, appropriate utilization of the expertise of GCs is paramount. We sought to describe the scope of activities that occupy GCs' time, distinguishing those that require utilization of GCs' unique skills and knowledge, from those that do not. Examination of this self-reported time utilization, together with an assessment of willingness to delegate diverse activities can inform efforts to support high-quality, efficient delivery of genetic counseling services.

Genetic counselors report spending more than half of their time (63.7\%) performing typical genetic counseling activities, as derived from the ACGC practice based-competencies, the ABGC practice analysis, and the 2014 NSGC Professional Status Survey. Not surprisingly, most GCs do not want to delegate their most time-consuming GC activities because they commonly feel that their training makes them uniquely prepared to carry out these roles and because they find these activities rewarding. Additionally, many of these activities have previously been identified by other medical providers as clear areas in which a GC provides value to a clinical team (Paneque et al., 2015). On the other hand, and as expected, the majority of respondents reported willingness to delegate some of their administrative activities. Given that respondents reported spending approximately $25 \%$ of their time performing administrative activities, this delegation could significantly improve efficiency, increase access to genetics services, improve quality of care, and allow more time for professional development activities, as noted in the qualitative data.

Importantly, re-allocation of GC time toward core responsibilities, direct patient care, and professional development, may also improve job satisfaction and reduce burnout. Numerous predictors of GC burnout have been described including role overload, conflicting role demands, and problems with work quality/output (Johnstone et al., 2016). Administrative issues, lack of support, and performing additional roles outside of one's scope of practice can lead to burnout, which may negatively impact quality of care (Block, Wu, Feldman, Yeh, \& Desai, 2013; Shanafelt, Bradley, Wipf, \& Back, 2002; West, Tan, Habermann, Sloan, \& Shanafelt, 2009). It may also lead to increases in GCs leaving clinical care positions, exacerbating the already prominent issue of providing care to a rapidly growing patient population (Cohen \& Tucker, 2018).

Delegation to numerous staff positions including personnel to manage insurance authorization (Uhlmann, Schwalm, \& Raymond, 2017), genetic counseling assistants (Pirzadeh-Miller et al., 2017), and additional clinical personnel (i.e. non-genetics professionals) can directly aid in the genetic counseling process (Cohen et al., 2013; Cohen \& Mcllvried, 2013; O'Shea et al., 2011). Given the variability among GC clinical specialties along with the tasks GCs felt were in their scope of practice, the most productive approach to delegation will likely vary across clinical settings. This conclusion is supported by recent research that showed significant variation between general and specialty genetics clinics with regard to time spent on tasks such as record review, insurance authorization, and literature review, highlighting that delegation or other tools for optimization will likely differ between clinics (Heald et al., 2016). Apart from delegation, GCs must also carefully consider other approaches to optimize utilization of their time and training. For example, many GC practices now make use of telephone/telemedicine genetic counseling models that have allowed them to reach a larger population base (Cohen et al., 2013; Kinney et al., 2014; National Society of Genetic Counselors, 2018; Platten et al., 2012). Additionally, numerous online tools have been created for both patients and providers to track family health information, input health information prior to an appointment, even to automate various parts of the genetic counseling process (Cohen \& Mcllvried, 2011; Doerr, Edelman, Gabitzsch, Eng, \& Teng, 2014; Pritzlaff et al., 2014). Online educational tools and videos can also be used to not only engage patients prior to undergoing genetic counseling, but may also be used as decision-making aids (Doerr et al., 2014; Sanderson et al., 2016; Yee et al., 2014). Tools such as these can help reduce average GC time per case (particularly in collection of family and medical history), improve consistency of care, aid in identifying appropriate referrals, as well as improve patient understanding (Cohen \& Mcllvried, 2011; Doerr et al., 2014; Pritzlaff et al., 2014).

Other professions have had to consider multifaceted approaches in improving efficiency and enabling practitioners to function at the top of their scope. The American College of Physicians has previously recognized the limitations that excess administrative tasks place on practitioners, and recommended a rigorous analytical approach involving numerous stakeholders to assess and address administrative burden on physicians (Erickson, Rockwern, Koltov, \& McLean, 2017). Increased effectiveness and efficiency are critical in the current changing healthcare system and are important to both leadership and administration. GCs need to demonstrate that they can increase their efficiency with the aid of more administrative support. For example, in a study on 
the practice effect of the addition of a genetic counseling assistant to a cancer genetics clinic, researchers showed a $58.5 \%$ increase in patient volume with a 3:1 ratio of GCs to genetic counseling assistants (Pirzadeh-Miller et al., 2017). It is therefore also important to recognize the utility of GCs within leadership positions that allow them to make similarly impactful changes to their practices. Multiple respondents in this study indicated institutional barriers to delegation, and GCs in other studies have noted lack of institutional/clerical support as common reasons for leaving their clinical positions (Cohen \& Tucker, 2018). While managerial and leadership training is not part of formal genetic counseling training, the development of this complementary expertise can create an administrator able to champion an environment where genetic counselors can function at the top of their scope of practice.

\section{1 | Practice implications}

Ultimately, GCs must reflect on their own clinical practices and identify factors that may hinder efficiency and the ability to support a growing patient population. Particularly in an era of genomic medicine in which genetic testing is becoming less expensive, more accessible, and has increasingly greater clinical utility, appropriate use of genetics training will be critical in ensuring that this population receives appropriate clinical care. The research presented here has identified multiple barriers to delegation, and while delegation should certainly be viewed as a useful tool to improve efficiency, it is not a comprehensive solution. This research has identified major time-consuming aspects of the genetic counseling field as a whole while showing that these can vary somewhat from clinic to clinic, and has identified numerous time-consuming tasks that GCs are willing to delegate. With this as a foundation, GCs should identify areas in their own clinical practices that represent an inadequate use of resources, determine what tools they may benefit from (i.e. delegation, technological modifications, etc.), and identify how they may go about implementing those tools as a means to not only improve efficiency, but also to increase their value added to their clinical teams.

\section{2 | Study limitations}

While we were able to identify numerous activities that GCs feel do not make appropriate use of their time and skill-set, top time-consuming activities, and the proportion of time spent within each of the three activity categories were self-reported and based on respondents' individual perceptions. As such, this study was not able to quantify the time allotted to specific activities, particularly those which most GCs would be willing to delegate, and is therefore subject to potential recall bias.

Furthermore, our assessment is limited to the 44 activities included in the survey. While this list was comprehensive and derived from the ACGC practice based-competencies, the ABGC practice analysis, and the 2014 NSGC Professional Status Survey, there are expected to be other activities which we were unable to detect using this methodology. Additionally, given the nature of the study design wherein respondents were only asked about willingness to delegate a specific activity if they previously indicated it as a top time consumer, activities that were not frequently selected as top time consumers (e.g. inventory of supplies) had relatively small sample sizes, limiting the utility of our analysis. That said, these activities are comparatively low in terms of how much time they cost the profession as a whole.

\section{3 | Research recommendations}

This study identified numerous differences between clinical specialties with regard to top time consumers, while also identifying tasks which many GCs would be willing to delegate. Additional research has since been performed, including a time study across multiple clinical specialties which identified that $64 \%$ of GC time was being spent on patient-related activities, including administrative activities, and $16 \%$ of time was being spend on tasks unrelated to patient care (Attard, Carmany, \& Trepanier, 2019). Ongoing research to determine how much of GC time is being spent on activities which may be appropriately delegated can allow for a better understanding of potential clinical and institutional/administrative impacts of delegation.

Furthermore, our study also showed substantial variability among clinical specialties, as well as individual GCs, with regard to willingness to delegate. As such, internal analyses within individual clinics can help identify activities that should be performed by a GC, which can be delegated to existing/new personnel (e.g. genetic counseling assistants), and what additional resources can be utilized to optimize GC efficiency.

\section{AUTHOR CONTRIBUTIONS}

Parker Read, Monica Marvin, Beverly Yashar, and Linda Robinson provided substantial contributions to the conception and/or design of the work, as well as the acquisition, analysis, and/or interpretation of data for the work, drafted the work and revised it critically for important intellectual content, provided final approval of the version to be published, and agree to be accountable for all aspects of the work in ensuring that questions related to the accuracy or integrity of any part of the work are appropriately investigated and resolved.

\section{ACKNOWLEDGMENTS}

The research presented in this manuscript was conducted to fulfill a degree requirement of the first author. Funding for this research was provided by the James V. Neel Genetic Counseling Fellowship and the University of Michigan Rackham Graduate School Student Research Grant.

\section{COMPLIANCE WITH ETHICAL STANDARDS}

\section{Conflict of interest}

All authors declare that they have no conflict of interest. 


\section{Human Studies And Informed Consent}

All procedures followed were in accordance with the ethical standards of the responsible committee on human experimentation (institutional and national) and with the Helsinki Declaration of 1975 , as revised in 2000 . This study was approved by the UM IRB (HUM00105474) and for this type of study formal consent was not required.

\section{Animal studies}

No nonhuman animal studies were carried out by the authors for this article.

\section{REFERENCES}

Accreditation Council for Genetic Counseling (2015). Practice-based competencies for genetic counselors. Retrieved from www.gcedu cation.org.

Attard, C. A., Carmany, E. P., \& Trepanier, A. M. (2019). Genetic counselor workflow study: The times are they a-changin'? Journal of Genetic Counseling, 28(1), 130-140. https://doi.org/10.1002/jgc4.1041

Block, L., Wu, A. W., Feldman, L., Yeh, H. C., \& Desai, S. V. (2013). Residency schedule, burnout and patient care among first-year residents. Postgraduate Medical Journal, 89(1055), 495-500. https://doi. org/10.1136/postgradmedj-2012-131743

Cohen, S. A., Marvin, M. L., Riley, B. D., Vig, H. S., Rousseau, J. A., \& Gustafson, S. L. (2013). Identification of genetic counseling service delivery models in practice: A report from the NSGC Service Delivery Model Task Force. Journal of Genetic Counseling, 22(4), 411421. https://doi.org/10.1007/s10897-013-9588-0

Cohen, S. A., \& Mcllvried, D. E. (2011). Impact of computer-assisted data collection, evaluation and management on the cancer genetic counselor's time providing patient care. Familial Cancer, 10(2), 381-389. https://doi.org/10.1007/s10689-011-9417-2

Cohen, S. A., \& Mcllvried, D. (2013). Improving access with a collaborative approach to cancer genetic counseling services: A pilot study. Community Oncology, 10(8), 227-234. https://doi.org/10.12788/ j.cmonc.0031

Cohen, S. A., \& Tucker, M. E. (2018). Movement of genetic counselors from clinical to non-clinical positions: Identifying driving forces. Journal of Genetic Counseling, 27(4), 792-799. https://doi. org/10.1007/s10897-018-0242-8

Concert Genetics (2018). The current landscape of genetic testing: market growth, reimbursement trends, challenges and opportunities. Retrieved from www.concertgenetics.com.

Cox, S. L., Zlot, A. I., Silvey, K., Elliott, D., Horn, T., Johnson, A., \& Leman, R. F. (2012). Patterns of cancer genetic testing: A randomized survey of Oregon clinicians. Journal of Cancer Epidemiology, 2012, 1-11. https ://doi.org/10.1155/2012/294730

Doerr, M., Edelman, E., Gabitzsch, E., Eng, C., \& Teng, K. (2014). Formative evaluation of clinician experience with integrating family history-based clinical decision support into clinical practice. Journal of Personalized Medicine, 4(2), 115-136. https://doi.org/10.3390/ jpm4020115

Erickson, S. M., Rockwern, B., Koltov, M., \& McLean, R. M. (2017) Putting patients first by reducing administrative tasks in healthcare: A position paper of the American College of Physicians. Annals of Internal Medicine, 166(9), 659-661. https://doi.org/10.7326/ m16-2697

Hampel, H., Grubs, R. E., Walton, C. S., Nguyen, E., Breidenbach, D. H., Nettles, S., ... Weik, L. A. (2009). Genetic counseling practice analysis. Journal of Genetic Counseling, 18(3), 205-216. https://doi. org/10.1007/s10897-009-9216-1

Hartmann, J. E., Veach, P. M., MacFarlane, I. M., \& LeRoy, B. S. (2015). Genetic counselor perceptions of genetic counseling session goals: A validation study of the reciprocal-engagement model. Journal of Genetic Counseling, 24(2), 225-237. https://doi.org/10.1007/ s10897-013-9647-6

Heald, B., Rybicki, L., Clements, D., Marquard, J., Mester, J., Noss, R., ... Eng, C. (2016). Assessment of clinical workload for general and specialty genetic counsellors at an academic medical center: A tool for evaluating genetic counselling practices. NPJ Genomic Medicine, 1, 16010. https://doi.org/10.1038/npjgenmed.2016.10

Hoskovec, J. M., Bennett, R. L., Carey, M. E., DaVanzo, J. E., Dougherty, M., Hahn, S. E., ... Wicklund, C. A. (2018). Projecting the supply and demand for certified genetic counselors: A workforce study. Journal of Genetic Counseling, 27(1), 16-20. https://doi.org/10.1007/ s10897-017-0158-8

IBM Corp (2015). IBM SPSS statistics for windows (Version 23.0). Armonk, NY: IBM Corp.

Johnstone, B., Kaiser, A., Injeyan, M. C., Sappleton, K., Chitayat, D., Stephens, D., \& Shuman, C. (2016). The relationship between burnout and occupational stress in genetic counselors. Journal of Genetic Counseling, 25(4), 731-741. https://doi.org/10.1007/ s10897-016-9968-3

Kinney, A. Y., Butler, K. M., Schwartz, M. D., Mandelblatt, J. S., Boucher, K. M., Pappas, L. M., ... Campo, R. A. (2014). Expanding access to BRCA1/2 genetic counseling with telephone delivery: A cluster randomized trial. Journal of the National Cancer Institute, 106(12), dju328. https://doi.org/10.1093/jnci/dju328

Kurian, A. W., Li, Y., Hamilton, A. S., Ward, K. C., Hawley, S. T., Morrow, M., ... Katz, S. J. (2017). Gaps in incorporating germline genetic testing into treatment decision-making for early-stage breast cancer. Journal of Clinical Oncology, 35(20), 2232-2239. https://doi.org/10.1200/ jco.2016.71.6480

Kurian, A. W., Ward, K. C., Hamilton, A. S., Deapen, D. M., Abrahamse, P., Bondarenko, I., ... Katz, S. J. (2018). Uptake, results, and outcomes of germline multiple-gene sequencing after diagnosis of breast cancer. JAMA Oncology, 4(8), 1066-1072. https://doi.org/10.1001/jamao ncol.2018.0644

Miller, C. E., Krautscheid, P., Baldwin, E. E., Tvrdik, T., Openshaw, A. S., Hart, K., \& Lagrave, D. (2014). Genetic counselor review of genetic test orders in a reference laboratory reduces unnecessary testing. American Journal of Medical Genetics Part A, 164(5), 1094-1101. https ://doi.org/10.1002/ajmg.a.36453

Mvundura, M., Grosse, S. D., Hampel, H., \& Palomaki, G. E. (2010). The cost-effectiveness of genetic testing strategies for Lynch syndrome among newly diagnosed patients with colorectal cancer. Genetics in Medicine, 12(2), 93-104. https://doi.org/10.1097/GIM.0b013e3181 cd666c

National Society of Genetic Counselors (2014). 2014 Professional status survey. Retrieved from www.NSGC.org.

National Society of Genetic Counselors (2018). 2018 Professional status survey. Retrieved from www.NSGC.org.

O'Shea, R., Murphy, A. M., Treacy, E., Lynch, S. A., Thirlaway, K., \& Lambert, D. (2011). Communication of genetic information by other health professionals: The role of the genetic counsellor in specialist clinics. Journal of Genetic Counseling, 20(2), 192-203. https://doi. org/10.1007/s10897-010-9337-6

Pan, V., Yashar, B. M., Pothast, R., \& Wicklund, C. (2016). Expanding the genetic counseling workforce: Program directors' views on increasing the size of genetic counseling graduate programs. Genetics in Medicine, 18(8), 842-849. https://doi.org/10.1038/ gim.2015.179

Paneque, M., Mendes, A., Guimaraes, L., Sequeiros, J., \& Skirton, H. (2015). Genetics health professionals' views on quality of genetic 
counseling service provision for presymptomatic testing in lateonset neurological diseases in Portugal: Core components, specific challenges and the need for assessment tools. Journal of Genetic Counseling, 24(4), 616-625. https://doi.org/10.1007/ s10897-014-9784-6

Pirzadeh-Miller, S., Robinson, L. S., Read, P., \& Ross, T. S. (2017). Genetic counseling assistants: An integral piece of the evolving genetic counseling service delivery model. Journal of Genetic Counseling, 26(4), 716-727. https://doi.org/10.1007/s10897-016-0039-6

Platten, U., Rantala, J., Lindblom, A., Brandberg, Y., Lindgren, G., \& Arver, B. (2012). The use of telephone in genetic counseling versus in-person counseling: A randomized study on counselees' outcome. Familial Cancer, 11(3), 371-379. https://doi.org/10.1007/ s10689-012-9522-x

Pritzlaff, M., Yorczyk, A., Robinson, L. S., Pirzadeh-Miller, S., Lin, T., Euhus, D., \& Ross, T. S. (2014). An internal performance assessment of CancerGene Connect: An electronic tool to streamline, measure and improve the genetic counseling process. Journal of Genetic Counseling, 23(6), 1034-1044. https://doi.org/10.1007/s10897-014-9732-5

Saldana, J. (2013). Chapter 3: First cycle coding methods. In J. Seaman (Ed.), The coding manual for qualitative researchers, 2nd ed. (pp. 67210). Thousand Oaks, CA: SAGE Publishing.

Sanderson, S. C., Suckiel, S. A., Zweig, M., Bottinger, E. P., Jabs, E. W., \& Richardson, L. D. (2016). Development and preliminary evaluation of an online educational video about whole-genome sequencing for research participants, patients, and the general public. Genetics in Medicine, 18(5), 501-512. https://doi.org/10.1038/gim.2015.118

Shanafelt, T. D., Bradley, K. A., Wipf, J. E., \& Back, A. L. (2002). Burnout and self-reported patient care in an internal medicine residency program. Annals of Internal Medicine, 136(5), 358-367. https://doi. org/10.7326/0003-4819-136-5-200203050-00008

Uhlmann, W. R., Schwalm, K., \& Raymond, V. M. (2017). Development of a streamlined work flow for handling patients' genetic testing insurance authorizations. Journal of Genetic Counseling, 26(4), 657-668. https://doi.org/10.1007/s10897-017-0098-3
VandenBoom, E., Trepanier, A. M., \& Carmany, E. P. (2018). Assessment of current genetic counselor practices in post-visit written communications to patients. Journal of Genetic Counseling, 27(3), 681-688. https://doi.org/10.1007/s10897-017-0163-y

West, C. P., Tan, A. D., Habermann, T. M., Sloan, J. A., \& Shanafelt, T. D. (2009). Association of resident fatigue and distress with perceived medical errors. JAMA, 302(12), 1294-1300. https://doi.org/10.1001/ jama.2009.1389

Wham, D., Vu, T., Chan-Smutko, G., Kobelka, C., Urbauer, D., \& Heald, B. (2010). Assessment of clinical practices among cancer genetic counselors. Familial Cancer, 9(3), 459-468. https://doi.org/10.1007/ s10689-010-9326-9

Yee, L. M., Wolf, M., Mullen, R., Bergeron, A. R., Cooper Bailey, S., Levine, R., \& Grobman, W. A. (2014). A randomized trial of a prenatal genetic testing interactive computerized information aid. Prenatal Diagnosis, 34(6), 552-557. https://doi.org/10.1002/ pd. 4347

\section{SUPPORTING INFORMATION}

Additional supporting information may be found online in the Supporting Information section.

How to cite this article: Read P, Yashar BM, Robinson L, Marvin M. Optimizing efficiency and skill utilization: Analysis of genetic counselors' attitudes regarding delegation in a clinical setting. J Genet Couns. 2020;29:67-77. https://doi. org/10.1002/jgc4.1181 